\title{
The Assessment of Practice and Challenges of Industries' Participation in Implementation of Occupational Competency Assessment: The Case of Addis Ababa City
}

\author{
Chekole Abrha Hayleyesus ${ }^{1}$, Brhanu Tsegay Mesele ${ }^{2}$ \\ ${ }^{1}$ Senior Research and Consultancy Expert at Addis Ababa Occupational Competency Assessment and Certification Center, Addis Ababa \\ Occupational Competency Assessment and Certification Center, Addis Ababa, Ethiopia \\ ${ }^{2}$ Department of Sociology, Wolaita Sodo University, Wolaita Sodo, Ethiopia
}

Email address:

chekoleabrha@gmail.com (C. A. Hayleyesus), dialectics.2006@gmail.com (B. T. Mesele), Brhanu@wsu.edu.et (B. T. Mesele)

\section{To cite this article:}

Chekole Abrha Hayleyesus, Brhanu Tsegay Mesele. The Assessment of Practice and Challenges of Industries' Participation in Implementation of Occupational Competency Assessment: The Case of Addis Ababa City. American Journal of Information Science and Technology. Vol. 4, No. 3, 2020, pp. 41-45. doi: 10.11648/j.ajist.20200403.11

Received: November 21, 2019; Accepted: May 25, 2020; Published: June 9, 2020

\begin{abstract}
This study was designed to assess practice and challenges of industries Participation in implementation of occupational competency assessment in Addis Ababa. A combination of quantitative and qualitative methods was used to achieve the objective of the study. Multi stage cluster sampling and Purposive sampling under non-probability sampling method was employed. The data were gathered using different data collection techniques which includes, survey, focus group discussion, key informant interview and in-depth interview. Data collected through various techniques were analyzed thematically. Study result of this research indicated that the current practice of industries participation in occupational competency assessment is too low. Industries practice and involvement in occupational competence assessment process in Addis Ababa is found very poor due to many factors. The finding indicated that, even though majority of manufacturing industries and hotels experts insured their competency by OCACC, significant number of employee was not certified. Low level of awareness/understanding about OCCAC, limited efforts of OCCAC and other stakeholders in rising awareness about the significance of active involvement of industries in occupational competence assessment process, high employee turnover, industries high emphasis on daily production, high interest of industries to employ unqualified and low skilled employees for wage purpose are some of the challenges that limit industries from active participation on occupational competence assessment process. Industries consider participation in an Implementation of Occupational Competency assessment as losing their production time and material. As a result, industries poor involvement in occupational competence assessment process has a great influence in creating quality assessment process and getting equipped and qualified experts for the industry sector.
\end{abstract}

Keywords: Practice, Challenges, Participation, Occupational Competence Assessment

\section{Introduction}

Different scholars tried to define the term competence in various ways. As to Dubois [3]; Lucia and Lepsinger [9], competency is the capability of applying or using knowledge, skills, abilities, behaviors and personal characteristics to successfully perform critical work tasks, specific functions or to operate in a given role or position.

Competencies are elements of the core competency of an organization that are difficult (if not impossible) for their competitors to match the study [12]. The development of distinctive competencies provides an organization with a competitive advantage because it allows the organization to take advantage of new opportunities in areas (sweet spots) where its competitors cannot function. To create and sustain a competitive advantage, the organization needs to integrate its core competencies and resources with its strategies in a competency-based management model.

The competencies required to perform each job in an organization can be determined through a competency mapping process that assumes there is a group of competencies required to successfully perform a particular 
job, and that the number of competencies for that particular job will depend on the nature of the work being done [14].

The competencies required for a particular job include the core competencies expected of all workers in the organization [13] as well as specific occupational or professional competencies associated with a particular job. These core competencies include knowledge, skills and abilities (commonly referred to as KSAs) as well as soft skills or behaviors [15].

Different countries have different views and approaches to the competency [16]. American approach to competency is behavioral approach which focuses on the importance of the individual characteristics and the behavioral competence as a means to develop better performance. UK functional approach is another approach to competency which is basically focusing on the functional analysis and developing occupational standards which are firmly rooted on the unit of competencies reflecting the reality in world of work.

UK is one of the earliest countries to develop comprehensive system of competency standards [16]. The France multidimensional, which focuses on knowledge, functional and behavioral competencies and the German holistic approach which defines competency as the capacity of a person to act holistically; comprising not only content or subject knowledge and ability, but also core and generic abilities [Getachew, 2014].

In Ethiopian Technical and Vocational Education and Training system, occupational competency assessment and certification is among the key activities stipulated in Technical and Vocational Education and Training (TVET) strategy [MoE, 2008]. It has been considered as very important activity to assure quality of training provision because assessment measures the quality of outcome of the training. Occupational assessment is conducted to collect evidence whether a person possesses competencies to do certain job as per defined in occupational standard or not.

Lythe cited in the study [6] like Germany, Australia and Philippines, has insured their development by implementing competency based technical and vocational training and occupational competency assessment. The Assessment and Certification System is the process of evaluating the TVET graduates and skilled workers to determine if trainees have acquired the desired level of competence to perform jobs in the workplace. The assessment and certification system involves the accreditation of assessors, the development of assessment tools, the qualification of TVET trainers as assessors, and the recognition/accreditation of National Assessment Agency across various sectors.

TVET operates at the interface of different sectors of society, notably the education sector, and the labor market industry. The TVET system must be steered and implemented with the involvement of a wide stakeholders group, [MOE, 2008]. Different stakeholders can contribute their own expertise, experience and capacities in order to improve the relevance and effectiveness of the TVET system and occupational competence assessment process.

To offer flexible, market oriented and demand based trainings, periodic assessment of the factors affecting the occupational competence assessment system being implemented is crucial. This can be done by making an adjustment on the training system in line with a changing economic context and the demand for different kinds of skills in the labor market.

Industries can get many advantages from occupational competency assessment and certification system such as: they can get competent work force, they can identify new employee and experienced workers based on their competency level to increase their salary and promotion, to increase the quality of product and to become competitive in national and international markets and enable industry owners to have great confidence on their workers capacity [Abnet, 2009].

Then industries participation in the implementation of occupational competency assessment and certification system has a vital role in preparation of occupational standards, providing assessment center, selecting efficient assessors from their industries and every industry expert should take an occupational competency assessment in each level.

Competency involves successful work performance (Offshore Petroleum Industry Training Organization, 2016).

According to Ethiopian TVET Strategy [MoE, 2008], TVET is to create a competent, motivated, adaptable and innovative workforce that plays pivotal roles in the poverty reduction and socio- economic development efforts of the country. This is achieved through facilitating demand-driven, self-employment oriented, relevant and outcome-based TVET at all levels.

Competency based training in Ethiopia lacks consultation with stake holders before implementation and this has resulted in being less effective [2]. In connection with this, [5] in his dissertation mentioned that integration and proper contextualization lacks in Ethiopian TVET system and this has to be improved; consultations with stake holders should be considered before interring into certain reform in education and training sector. In outcome based system, identified competences of the labor market that are described in the occupational standards are the final benchmarks not only for training and learning activities but also for the assessment of competences and certification as well [MoE, 2008]. Building an outcome-based TVET system creates access for equal recognition of competences acquired through whatever the means and ways of being competent [Georgeta, 2013].

Industries which are found in a city government of Addis Ababa, owners and occupational competency assessment center experts were participated in the study.

City government of Addis Ababa Occupational Competency Assessment and Certification Center started its work officially since 2008 and plays its role in producing competent citizen to industries. Until September 2018,792,596 candidates were assessed in various occupations from these $413,708(52.2 \%)$ were found to be competent [OCACC, 2008].

This indicates as there is a problem in producing skilled and 
competent experts who might be get employed in the industry sector. In spite of some trials, little has been done so far with regard to the quality, efficiency and effectiveness of Competence of Occupational Assessment in Addis Ababa city Administration [OCACC, 2013]. In many research workshops and discussion seminars, it is reported that industries practice and participation in occupational competence assessment process is too low. However, data related to the challenges that inhibit the practice and participation of industries in occupational competence assessment process is quite limited. Hence, the aim of this research was to assess the practice and describe the challenges that inhibit industries from active participation in occupational competence assessment process in Addis Ababa.

\section{Methodology}

So as to achieve objective of the study, qualitative and quantitative study approaches has been used. The research is a cross sectional study; aimed at collecting data at one point in time and describing the study population rather than showing the patterns of change which might be witnessed over time.

The study employed primary and secondary data sources. The sources of the information were survey respondents, focus groups and key informants. The secondary sources of information include books, articles, research journals, and different reports. Key informant interviews, focus group discussions, in-depth interviews and survey used asdata collection techniques. Structured and Semi-structured checklists were designed to manage the survey, focus group discussions, Key informant interviews, and in-depth interviews. 48 industries were selected (30 from manufacturing- metal and textile and 18 from the service sector- international hotels). This was done purposively because these are government focused industries. 336 respondents 7 from each industry were selected depending on their experience. Finally, data were collected from 315 sample respondents. See table1 below.

Tabe 1. Distribution of sample respondents.

\begin{tabular}{lllll}
\hline & Industry sector & Number of sample industries & Sample experts & Collected Questionnaires \\
\hline 1 & Manufacturing industries & 30 & 210 & 195 \\
2 & International hotels & 18 & 126 & 121 \\
& Total & 48 & 336 & 315 \\
\hline
\end{tabular}

In-depth interviews were made with four purposively selected senior occupational assessment directorate directors. Inaddition, three focus group discussions (10 individuals in each group) were carried out. Qualitativeand quantitative information was analyzed thematically. Qualitative information recorded on notebook from FGDs, and in-depth interviewswere organized and constructed coherently, analyzed in word description form. SPSS version 21 was used as a tool to analyze quantitative information gathered through the survey instrument. The analysis was done using descriptive statistical analysis i.e. frequency distributions, percentages.

\section{Study Results}

This section of the paper deals with data presentation and analysis of the data collected by using the different data collection tools such as, survey, in-depth interview, key informant interview, and focus group discussion.

Table 2. Respondents'status whether they have taken occupational competence assessment.

\begin{tabular}{|c|c|c|c|c|}
\hline \multirow{2}{*}{ Variable } & \multicolumn{2}{|l|}{ Yes } & \multicolumn{2}{|l|}{ No } \\
\hline & $\mathbf{F}$ & $\%$ & $\mathbf{F}$ & $\%$ \\
\hline Did you take occupational competency assessment? & 192 & 60.9 & 123 & 39.1 \\
\hline
\end{tabular}

As indicated in the table above, among the survey respondents who were asked whether they did take occupational competence assessment, 192 (60.9\%) of industry experts has taken an occupational competency assessment while $123(39.1 \%)$ did not insure their competency. This shows that though majority of industry experts took an assessment, a significant number of the experts were not involved.

Table 3. Experts level of awareness about competence assessment.

\begin{tabular}{|c|c|c|c|c|}
\hline \multirow{2}{*}{ Variable } & \multicolumn{2}{|l|}{ Yes } & \multicolumn{2}{|l|}{ No } \\
\hline & $\mathbf{F}$ & $\%$ & $\mathbf{F}$ & $\%$ \\
\hline Do you think all experts who work in your industry have sufficient information about competency assessment? & 207 & 65.7 & 108 & 34.3 \\
\hline
\end{tabular}

As shown in table 2, majority, 207 (65.7\%) of the sample respondents in the survey reported that experts working in their industry do have sufficient information about competency assessment while the remaining 108 (34.8\%) thought that do not have.

Table 4. Knowhow of industry workers with no/ low educational status about taking competency assessment.

\begin{tabular}{|c|c|c|c|c|}
\hline \multirow{2}{*}{ Variable } & \multicolumn{2}{|l|}{ Yes } & \multicolumn{2}{|l|}{ No } \\
\hline & $\mathbf{F}$ & $\%$ & $\mathbf{F}$ & $\%$ \\
\hline Do all experts with no education work in your industry know as they can take competency assessment? & 175 & 55.5 & 140 & 44.4 \\
\hline
\end{tabular}


As indicated in the above table, 175 (55\%) of the respondents assumed that workers who have no education but work in their industry knows that they can take occupational competence whereas the remaining $140(44.6 \%)$ assumed that they are not aware whether they can take competence assessment.

Table 5. Knowhow of experts about occupational competence assessor selection criteria.

\begin{tabular}{llll}
\hline Variable & Yes & No \\
\cline { 2 - 4 } & F & \% & F \\
\hline $\begin{array}{l}\text { As an industry expert, do you know the criteria used to select occupational } \\
\text { competency assessors and occupational competency assessment center? }\end{array}$ & 95 & 30.2 & 220 \\
\hline
\end{tabular}

As can be seen in the above table, 95 (30.2\%) of industry experts know assessor selection criteria of occupational competency assessment center but majority 220 (69.8\%) of participant didn't know the assessor selection criteria in occupational competence assessment center.

Table 6. Prevalence of any system to select occupational competence assessor.

\begin{tabular}{|c|c|c|c|c|}
\hline \multirow{2}{*}{ Variable } & \multicolumn{2}{|l|}{ Yes } & \multicolumn{2}{|l|}{ No } \\
\hline & $\mathbf{F}$ & $\%$ & $\mathbf{F}$ & $\%$ \\
\hline In your industry, is there any system of assessor selection for occupational competence & 128 & 40.4 & 187 & 59.6 \\
\hline
\end{tabular}

As can be seen in the above table, 128 (40.4\%) of industry experts know selection criteria for occupational competency assessment assessor but majority 187 (59.6\%) of the experts didn't know the assessor selection criteria in occupational competence assessment center. As indicated in table above, some of the respondents are aware of the assessor selection criteria; significant number of the respondents did not know selection criteria of assessors and occupational assessment centers.

Table 7. Voluntariness of industries to become occupational competence assessment center.

\begin{tabular}{|c|c|c|c|c|c|c|}
\hline \multirow{2}{*}{ Variable } & \multicolumn{2}{|c|}{ Yes } & \multicolumn{2}{|l|}{ No } & \multicolumn{2}{|c|}{ Undecided } \\
\hline & $\mathbf{F}$ & $\%$ & $\mathbf{F}$ & $\%$ & $\mathbf{F}$ & $\%$ \\
\hline Was your industry volunteer to become occupation competence assessment center? & 90 & 28.6 & 147 & 46.7 & 78 & 24.7 \\
\hline
\end{tabular}

Based on the results shown in the above table, $90(28.6 \%)$ of the respondents industries are not willing to become occupational competence assessment center. On the contrary, $147(46.7 \%)$ of them reported that industries are willing to become occupational competence assessment centers. The remaining $78(24.7 \%)$ of the respondents, fails to conclude whether industries are willing or not to become occupational competence assessment center. in others words these respondents unable to decide the willingness of industries in this regard.

\section{Discussion Results}

Major challenges that limit industries' practice and participation in occupational competence assessment process

Majority of the study participants in the FGDs and indepth interview and key informant interviews noted that active participation of industries in Implementation of Occupational Competency Assessment is mandatory. On the contrary, some study participants from the FGD slightly understands about the Importance of active participation of industries in Implementation of Occupational Competency Assessment. According to the discussion participants in this study, the main challenges that limit the industries not to actively practice and participate in Implementation of Occupational Competency Assessment include, Low level of awareness/understanding about OCACC, industry counsel of chambers by themselves have low intention to wards guiding assessment.
Besides, some of industry owners and managing directors want to employ many unskilled individuals with low wages than few skilled experts. The intention here is to produce more and more products focusing on the quantity rather than product quality. Since majority of industry were product oriented, they are not volunteer to provide assessment center and selecting assessors from their staff. Furthermore, industries consider participation in an Implementation of Occupational Competency assessment as losing their production time and material. Industries view towards TVET and OCACC is found below expected because they believe that in some occupations training and assessment were not given as industries need or trainee cannot fit with new industry'swork environment. Due to that industry owners introduce new machineries by giving training again. [11]

According to the discussion participants in this study, industries involvement to become owner of occupational competency assessment system is found very poor. Besides, discussion results of this study showed that industries poor involvement in occupational competence assessment process has a great influence creating quality implementation of assessment process and getting equipped and qualified experts for industry sector. According to the study participants, OCACC staffs need to study the status, capacity and specific needs of industries. Accordingly, providing appropriate support such as continuous follow-up, assessment tools and enhances their capacity to become standardized competence centers. 


\section{Conclusion}

This study was conducted with the major objective of investigating practice and challenges of Industries Participation in Implementation of Occupational Competency Assessment: the case of Addis Ababa city. Both quantitative and qualitative methodologies were used to examine the objectives set out before the actual study. Survey, in-depth interviews, key-informant interviews, focus group discussion were used to collect data relevant to the study. The data collected using the quantitative and qualitative data collection tools were analyzed thematically.

Industries practice and involvement in occupational competence assessment process in Addis Ababa is found very poor due to many factors. The finding indicated that, even though majority of manufacturing industries and hotels experts insured their competency by OCACC, significant number of employee was not certified.

Low level of awareness/understanding about OCCA, and its significance, excessive concern on daily production, limited support of occupational competence assessment center staffs of the city, and high employee turnover are some of the reasons that limit the participation of industries in occupational competence assessment process. Besides, some of industry owners and managing directors want to employ many unskilled individuals with low wages than few skilled experts. Since majority of industry were product oriented, they are not volunteer to provide assessment center and selecting assessors from their staff. Furthermore, industries consider participation in an Implementation of Occupational Competencyassessment as losing their production time and material. As a result, industries poor involvement in occupational competence assessment process has a great influence in creating quality assessment process and getting equipped and qualified experts for the industry sector.

\section{Recommendation}

Considering the importance of active participation of various stakeholders including industries in advancement occupational competence assessment centers and getting equipped and certified experts for the industry, more is needed to be done. Occupational competence assessment center of the city needs to investigate the specific contexts that limit industries from active involvement in the occupational competence assessment process, held awareness rising seminars about the importance of active involvement of industries in occupational competence assessment process and being a center of occupational assessment center.

Furthermore, supports given to industries should be context specific and based on their capacity and interest. The OCACC should collaborate with the ministry of trade and industry, industry parks Development Corporation, federal investment commission and industry development institutes which have strong relationship with industries, provide forum with these federal government institutions to enhance the participation level of industries in occupational competence assessment process.

\section{References}

[1] Abnet Falasa (2010). Basic ways to make effective in occupational competency assessment.

[2] Baraki H., Worku N., Melesse A. (2016). Evaluating the Implementations of Competence-Based Assessment and Certification System in TVET: The Case of Ethiopia; Research on Humanities and Social Sciences ISSN (Paper) 2224-5766 ISSN (Online) 2225-0484 (Online) Vol. 6, No. 9, 2016.

[3] Dubois, D. D. (1993). Competency-Based Performance Improvement: A Strategy for Organizational Change, HRD Press, Inc., Amherst, MA.

[4] Essam O. Ahmed and George M. Bodner (2017). Developing of occupational standards and their impact in capacity building Journal of Management Development, https://www.researchgate.net/publication/313992793.

[5] Getachew H. (2016). Towards Competence based technicalVocational Education and Training in Ethiopia. Addis Ababa, Ethiopia.

[6] Getachew Tadesse (2014). an Assessment in Occupational Competence and Certification System of Technical and Vocational Education and Training in Selected Government Institutions of Addis Ababa City Administration, Addis Ababa University, unpublished thesis.

[7] Georgeta Pelcea (2013). Assessment and certification of competences acquired in informal and non-formal learning contexts referred to the occupational standards Context of Romania. Romania.

[8] LE DEIST, F. D. \& WINTERTON, J. (2005). What Is Competence? Human Resource Development International, 8, 27-46.

[9] Lucia, A. D. and Lepsinger, R. (1999). The Art and Science of Competency Models: Pinpointing Critical Success Factors in Organizations, Pfeiffer, New York, NY.

[10] MOE (2008). National Technical and Vocational Education and Training (TVET) Strategy. Addis Ababa: Federal Democratic Republic of Ethiopia, Ministry of Education (MoE).

[11] OCACC (2013). Dominant factors affecting candidates' occupational competency: City government of Addis Ababa Occupational Competency Assessment and Certification Center, Addis Ababa: Ethiopia, unpublished research.

[12] Prahalad, C. K. and Hamel, G. (1990). "The core competence of the cooperation", Harvard Business Review.

[13] Rothwell, W. J. (2002). The Workplace Learner: How to Align Training Initiatives with Individual Learning Competencies, American Management Association, New York, NY.

[14] Shippman, J. S., Ash, R. A., Battista, M., Carr, L., Eyde, L. D., Hesketh, B., Kehoe, J., Pearlman, K. and Sanchez, J. I. (2000). "The practice of competency modeling", Personnel Psychology, Vol. 53, pp. 703-740.

[15] Spencer, L. M. and Spencer, S. M. (1993). Competence at Work, Wiley, New York, NY.

[16] Stan Lester and Jolanta Religa (2016). 'Competence' and occupational standards: observations from six European countries. 